\title{
Assault-related admissions to hospital in Central Australia
}

\author{
Ged F Williams, Wendy P Chaboyer and Philip J Schluter
}

A PERCEIVED INCREASE in serious assault and violence in Australia has received periodic intense media and public scrutiny. The focus is often on marginalised or minority groups, including Aboriginal people. ${ }^{1-3}$ The personal, social and community effects of serious assault are well described and may be associated with substance misuse, poverty and cultural fragmentation. ${ }^{4,5}$

National surveys of assault in Australia demonstrate a range of demographic and social differences. Of the 618300 people over the age of 15 assaulted in a 12-month period before 1998, 54\% were male. ${ }^{6}$ The Australian Capital Territory $(6.9 \%)$ and the Northern Territory (6.3\%) had the greatest proportions of their population assaulted, whereas the national rate was $4.3 \% .^{6}$ Force or violence was associated with assaults in 245000 (39.7\%) cases, and $13300(2.2 \%)$ assaulted people were admitted to hospital. ${ }^{6}$

Data relating to the Indigenous population are generally of poorer quality and most reports are anecdotal. ${ }^{7}$ In one study, the Indigenous age-adjusted rate of hospitalisation per 100000 was 17 times the national rate. ${ }^{8}$ Hospitalisation resulting from interpersonal violence was generally similar for male and female Aboriginals, but the rate of hospitalisation both for unarmed fights or brawls and for attack by cutting or piercing instruments was higher for men aged 15-49 years than for women of the same age. ${ }^{8}$

\section{ABSTRACT}

Objective: To determine the number of assault-related admissions to hospital in the Central Australia region of the Northern Territory over a six-year period.

Design and setting: Retrospective analysis of all patients admitted to Alice Springs Hospital (ASH) and Tennant Creek Hospital (TCH) from July 1995 to June 2001, where the primary cause of injury was "assault".

Main outcome measures: Frequency of assault-related admission to hospital; demographic characteristics of the victims.

Results: In the six years, there were 2449 assault-related admissions to ASH and 545 to TCH. Adults aged 25-34 years were most frequently hospitalised for assault, in a proportion greater than their proportion in the NT population. Females represented $59.7 \%$ of people admitted to $\mathrm{ASH}$ and $54.7 \%$ to $\mathrm{TCH}$, greater than their proportion in the NT population. Aboriginals comprised $95.2 \%$ of $\mathrm{ASH}$ and $89.0 \%$ of $\mathrm{TCH}$ admissions, and were admitted in a significantly greater proportion than their proportion in the NT population $(P<0.001)$. The age-adjusted hospital admission rate resulting from assault has increased $(P=0.002)$ at an average rate of 1.6 (SE, $0.2)$ per 10000 people per year. The proportion of assault-related admissions associated with alcohol has also increased significantly $(P<0.001)$.

Conclusion: The frequency of assault-related admissions to hospital, especially among the Aboriginal population, suggests that this major public health issue is escalating.

MJA 2002; 177: 300-304

The purpose of our study was to describe the number of admissions to hospital that were directly related to assault (using a six-year retrospective analysis of computerised hospital data) and to examine factors associated with these admissions.

\section{METHODS}

Our data are from Alice Springs Hospital (ASH) and Tennant Creek Hospital (TCH), the only two hospitals in the

\section{For editorial comment, see page 286}

NT Department of Health and Community Services, Alice Springs Hospital,

Alice Springs, NT.

Ged F Williams, RN, FRCNA, Executive Director of Nursing Services, Alice Springs Hospital, Associate

Professor of Nursing, Flinders University and Northern Territory University.

School of Nursing - Gold Coast, Griffith University, Southport, QLD.

Wendy P Chaboyer, RN, PhD, Associate Professor.

School of Population Health, University of Queensland, Brisbane, QLD.

Philip J Schluter, MSc(Distinction), PhD, Associate Professor of Biostatistics.

Reprints will not be available from the authors. Correspondence: Associate Professor G F Williams, NT

Department of Health and Community Services, Alice Springs Hospital, PO Box 2234, Alice Springs,

NT 0871. ged.williams@nt.gov.au

Central Australia region of the NT. ASH is a 160-bed, general regional hospital, providing emergency, intensive care, and most other acute services. $\mathrm{TCH}$ is a 20 -bed community hospital, $500 \mathrm{~km}$ north of Alice Springs. The catchment area for these hospitals is more than 1 million $\mathrm{km}^{2}$ and has a residential population of 47000 , of whom about $40 \%$ are Aboriginal. ${ }^{9}$

Electronic records of all admissions to ASH and TCH between 1 July 1995 and 30 June 2001 were examined, and admission with the primary cause of injury as "assault" were extracted. Demographic data were collected using the Business Objects program, a hospital-based software system. Additional information from the electronic records identified alcohol use, repeated admissions and, for $\mathrm{ASH}$, the cause of the assault. Data were de-identified and grouped to preserve the anonymity of subjects and communities, as required by the Institutional Ethics Committee, and Aboriginal subcommittee, who approved our study. 
In July 1998, the NT moved from ICD-9-CM to ICD-10-AM coding. The codes used for the two time periods are displayed in Box 1. Data entered into the ICD system are dependent on hospital coders examining individual patient records. The coders identify medical staff entries that refer to specific events (eg, alcohol present on admission, or blunt trauma). This information is translated into ICD codes and entered into an electronic database. At $\mathrm{ASH}$, the same two hospital coders were responsible for all patient data entries for the six years of the study. These coders also monitored TCH data entry.

When patients were admitted to $\mathrm{TCH}$ and then transferred to ASH for a single assault-related admission, the episode was counted only once, and for TCH.

\section{Statistical analysis}

Frequencies (percentages) were used to report categorical variables, and associations between groups were assessed using Pearson's $\chi^{2}$ test and CochranArmitage's trend test. Estimated resident population by age, sex and Indigenous status ${ }^{9}$ was used to calculate admission rates. Age-adjusted rates were calculated using Australian Bureau of Statistics (ABS) census figures for the NT population in 2001 as the standard. ${ }^{9}$ Assuming admission rates follow a Poisson distribution, 95\% confidence intervals were calculated using computer simulation of size $n=10000$. Linear regression was used to evaluate trends in the rates over time, and annual change estimates and standard errors are given. A significance level of $\alpha=0.05$ was used for all comparisons.

\section{RESULTS}

There were 2994 assault-related admissions between July 1995 and June 2001: $2449(81.8 \%)$ at ASH and 545 (18.2\%) at $\mathrm{TCH}$ (Box 2). People aged 25-34 years, women, and Aboriginals accounted for significantly greater proportions of assault-related admissions than expected from their proportions in the NT population in 2001 (Box 2).

Box 3 displays crude assault-related admission rates per 10000 people at $\mathrm{ASH}$ and $\mathrm{TCH}$ combined. While the

\begin{tabular}{lcc} 
1: Coding classification of assault-related hospital admissions \\
$\begin{array}{lcc}\text { July 1995 to June 1998 } \\
\text { (ICD-9-CM codes) }\end{array}$ & $\begin{array}{c}\text { July 1998 to June 2001 } \\
\text { (ICD-10-AM codes) }\end{array}$ \\
\hline Assault & E968.2 & Y00 \\
Blunt object & E966. & X99 \\
Sharp object & E968. & X97 \\
Fire & E960. & Y04 \\
Force (excluding rape) & E960.1 & Y05 \\
Rape & & F10.1 \\
Alcohol use & $305.00-305.02$ & F10.0 \\
Alcohol use disorder & $303.00-303.02$ & F10.2 \\
Acute drunkenness and alcoholism & $303.90-303.92$ & F10.3-F10.4 \\
Alcohol dependence & $291.0-291.9$ & \\
Alcohol withdrawal & & \\
\hline †Acute intoxication only. & &
\end{tabular}

\section{2: Demographic characteristics of people admitted to Alice Springs Hospital (ASH) and Tennant Creek Hospital (TCH) for assault, July 1995 to June 2001}

\begin{tabular}{|c|c|c|c|c|c|c|}
\hline & ASH $(n=2449)$ & $\mathrm{TCH}(n=545)$ & $P^{*}$ & Total $(n=2994)$ & $\mathrm{ABS}^{\dagger}(n=197590)$ & $P^{*}$ \\
\hline \multicolumn{7}{|l|}{ Age (years) } \\
\hline$\leqslant 14$ & $42(1.7 \%)$ & $24(4.4 \%)$ & & $66(2.2 \%)$ & $51103(25.9 \%)$ & \\
\hline $15-24$ & $372(15.2 \%)$ & $69(12.7 \%)$ & & $441(14.7 \%)$ & $31126(15.7 \%)$ & \\
\hline $25-34$ & $916(37.4 \%)$ & $227(41.7 \%)$ & $<0.001$ & $1143(38.2 \%)$ & 38257 (19.4\%) & $<0.001$ \\
\hline $34-44$ & $728(29.7 \%)$ & $152(27.9 \%)$ & & $880(29.4 \%)$ & 32472 (16.4\%) & \\
\hline$\geqslant 45$ & $391(16.0 \%)$ & $73(13.4 \%)$ & & $464(15.5 \%)$ & $44632(22.6 \%)$ & \\
\hline \multicolumn{7}{|l|}{ Sex } \\
\hline Male & $986(40.3 \%)$ & $247(45.3 \%)$ & 0.03 & $1233(41.2 \%)$ & 104326 (52.8\%) & $<0.001$ \\
\hline Female & $1463(59.7 \%)$ & $298(54.7 \%)$ & & $1761(58.8 \%)$ & $93264(47.2 \%)$ & \\
\hline \multicolumn{7}{|l|}{ Ethnicity ${ }^{\ddagger}$} \\
\hline Aboriginal & $2210(95.2 \%)$ & $485(89.0 \%)$ & $<0.001$ & 2695 (94.0\%) & $56364(28.5 \%)$ & $<0.001$ \\
\hline Non-Aboriginal & $112(4.8 \%)$ & $60(11.0 \%)$ & & $172(6.0 \%)$ & $141226(71.5 \%)$ & \\
\hline
\end{tabular}

non-Aboriginal rate was constant over the study period (test for non-zero linear slope, $P=0.96$ ), the Aboriginal rate was much higher and significantly increased at an average rate of 2.4 (SE, $0.5)$ per 10000 people per year $(P=0.006)$. The relative ratio for Aboriginal/non-Aboriginal crude rates was 31.6 in 1995-96, increasing to 43.8 in 2000-01.

The total number of admissions due to all causes (excluding day-only cases) at the two hospitals during the study period was only accessible from July 1997. The overall proportion of hospital admissions resulting from assault significantly increased from $4.2 \%$ in $1997-98$ to $4.8 \%$ in $2000-01 \quad(P=0.02)$. This increase in proportions was evident in ASH admissions, increasing from 3.8\% to $4.7 \%(P=0.003)$, but not in $\mathrm{TCH}$ admissions, decreasing from $6.9 \%$ to $5.0 \%(P=0.05)$.

Box 4 provides age-adjusted assaultrelated admission rates per 10000 for the two hospitals combined over the study period. Each of these rates had a significant linear increase over time: females, 2.4 (SE, 0.3) per 10000 people per year $(P=0.001)$; males, 0.9 
(SE, 0.3) per 10000 people per year $(P=0.05)$; and overall, 1.6 (SE, 0.2) per 10000 people per year $(P=0.002)$.

The proportion of assault-related admissions involving alcohol increased from $29.9 \%$ in $1995-96$ to $43.0 \%$ in 2000-01 ( $P<0.001)$; however, the rates have remained steady since 1997$98(P=0.92)$ (Box 5).

The primary causes of assault-related admissions by year for ASH (TCH information was not accessible) appear in Box 6. Prior to 1999-00, blunt trauma was the most frequent cause of these admissions, although significantly decreasing over the study period $(P<0.001)$. A trend of increasing use of sharp objects was evident $(P<0.001)$, with physical force $(P=0.25)$, other $(P=0.31)$, and not recorded $(P=0.14)$ remaining stable. Fire was involved in 29 $(1.2 \%)$ ASH assault-related admissions and rape in $19(0.8 \%)$. Primary cause data were missing in less than $10 \%$ of observations.

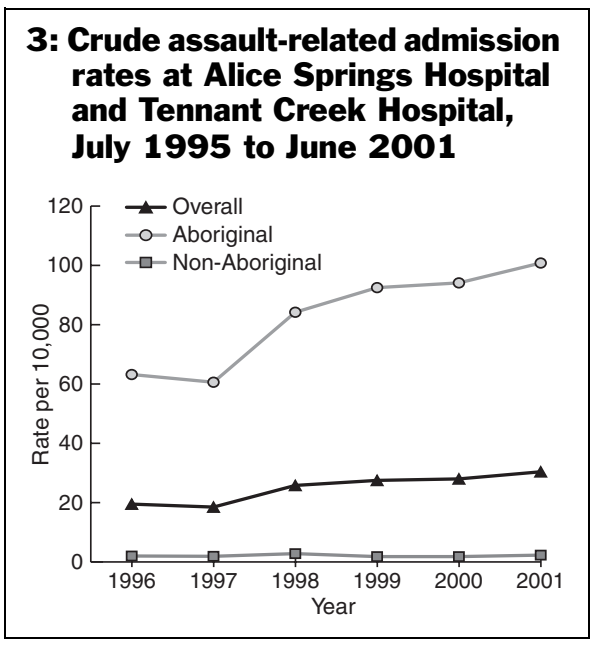

\section{DISCUSSION}

We found that assault-related admissions to the only two hospitals in Central Australia significantly increased over the six years to 2001 .

Adults aged between 25 and 44 years were most likely to be admitted to hospital for assault-related causes. A study in Victoria in 1997 found that $40 \%$ of people presenting to emergency departments because of assault were aged 2544 years, ${ }^{10}$ somewhat lower than the $68 \%$ in our study.

Women were admitted for assaultrelated injuries more frequently than expected from their population frequency, a finding contrary to previous reports. $^{4,6,8,10}$ In provincial Victoria, males were more likely to present to the emergency department because of assault. ${ }^{10}$ In the NT, males comprised $53 \%$ of the population from 1979 to 1995 , but made up $77 \%$ of the violence-related deaths, while a third of all injury-related deaths among Aboriginal women in the NT are due to homicide. ${ }^{11}$ There are several possible reasons why women appeared to be more at risk of assault in our study than in previous ones. The Central Australian population, with $40 \%$ Aboriginals, is likely to be quite different to populations in other studies. Alcohol consumption is high in this population, and this might have an influence. ${ }^{12,13}$ Finally, our data do not include individuals who were assaulted but not admitted to hospital, or those who died before hospitalisation.

It is striking that the proportion of hospital admissions due to assault fell at $\mathrm{TCH}$ while it rose at ASH. This warrants further consideration.

Aboriginals greatly outnumbered non-Aboriginals, comprising more than $90 \%$ of the admissions, significantly higher than the $40 \%$ they represent in the Central Australian population. Although the assault-related admissions

\begin{tabular}{|c|c|c|c|c|c|c|}
\hline \multicolumn{7}{|c|}{$\begin{array}{l}\text { 4: Age-adjusted annual assault-related admission rates per } 10000 \text { people } \\
\text { to Alice Springs Hospital and Tennant Creek Hospital, July } 1995 \text { to } \\
\text { June } 2001 \text {, standardised to the Northern Territory } 2001 \text { population }\end{array}$} \\
\hline \multirow[b]{2}{*}{ Year } & \multicolumn{2}{|c|}{ Female } & \multicolumn{2}{|c|}{ Male } & \multicolumn{2}{|c|}{ Total } \\
\hline & Rate & $(95 \% \mathrm{Cl})^{\star}$ & Rate & $(95 \% \mathrm{Cl})^{*}$ & Rate & $(95 \% \mathrm{Cl})^{\star}$ \\
\hline 1995-96 & 26.5 & $(23.1-29.9)$ & 19.2 & $(16.4-22.0)$ & 22.7 & $(20.6-24.9)$ \\
\hline 1996-97 & 27.2 & $(23.8-30.7)$ & 17.6 & $(15.0-20.2)$ & 22.2 & $(20.1-24.3)$ \\
\hline 1997-98 & 31.9 & $(28.2-35.7)$ & 20.7 & $(18.0-23.7)$ & 26.0 & (23.7-28.3) \\
\hline 1998-99 & 34.8 & $(31.0-38.6)$ & 20.7 & $(18.0-23.7)$ & 27.4 & $(25.1-29.7)$ \\
\hline 1999-00 & 36.5 & $(32.7-40.5)$ & 20.3 & $(17.6-23.0)$ & 27.9 & $(25.6-30.3)$ \\
\hline 2000-01 & 37.4 & (33.5-41.3) & 24.1 & $(21.3-27.1)$ & 30.4 & $(28.1-32.8)$ \\
\hline
\end{tabular}

\section{5: Alcohol-associated assault admissions $(n)$ as a proportion of the total assault admissions ( $M$ ) for Alice Springs Hospital and Tennant Creek Hospital between July 1995 and June 2001}

\begin{tabular}{|c|c|c|c|c|c|c|c|c|c|c|}
\hline \multirow[b]{3}{*}{ Year } & \multicolumn{4}{|c|}{ Alice Springs Hospital } & \multicolumn{4}{|c|}{ Tennant Creek Hospital } & & \\
\hline & \multicolumn{2}{|c|}{ Female } & \multicolumn{2}{|c|}{ Male } & \multicolumn{2}{|c|}{ Female } & \multicolumn{2}{|c|}{ Male } & \multicolumn{2}{|c|}{ Overall } \\
\hline & $\mathrm{n} / \mathrm{N}$ & (\%) & $\mathrm{n} / \mathrm{N}$ & (\%) & $\mathrm{n} / \mathrm{N}$ & (\%) & $n / N$ & (\%) & $\mathrm{n} / \mathrm{N}$ & (\%) \\
\hline 1995-96 & $47 / 179$ & $(26.3 \%)$ & $57 / 131$ & $(43.5 \%)$ & $11 / 47$ & $(23.4 \%)$ & $6 / 48$ & $(12.5 \%)$ & $121 / 405$ & $(29.9 \%)$ \\
\hline $1996-97$ & $50 / 183$ & $(27.3 \%)$ & $44 / 127$ & $(34.6 \%)$ & $18 / 60$ & $(30.0 \%)$ & $17 / 46$ & $(37.0 \%)$ & $129 / 416$ & $(31.0 \%)$ \\
\hline 1997-98 & $98 / 229$ & $(42.8 \%)$ & $80 / 160$ & $(50.0 \%)$ & $13 / 58$ & $(22.4 \%)$ & $24 / 48$ & $(50.0 \%)$ & $215 / 494$ & $(43.5 \%)$ \\
\hline 1998-99 & $106 / 271$ & $(39.1 \%)$ & $82 / 171$ & $(48.0 \%)$ & $20 / 48$ & $(41.7 \%)$ & $19 / 41$ & $(46.3 \%)$ & $227 / 531$ & $(42.7 \%)$ \\
\hline 1999-00 & 99/280 & $(35.4 \%)$ & $97 / 180$ & $(53.9 \%)$ & $28 / 57$ & $(49.1 \%)$ & $18 / 30$ & $(60.0 \%)$ & $242 / 547$ & $(44.2 \%)$ \\
\hline $2000-01$ & $136 / 321$ & $(42.4 \%)$ & $95 / 217$ & $(43.8 \%)$ & $12 / 28$ & $(42.9 \%)$ & $15 / 34$ & $(44.1 \%)$ & $258 / 600$ & $(43.0 \%)$ \\
\hline Total & $536 / 1463$ & $(36.6 \%)$ & $455 / 986$ & $(46.1 \%)$ & $102 / 298$ & (34.2\%) & $99 / 247$ & $(40.1 \%)$ & $1192 / 2994$ & (39.8\%) \\
\hline
\end{tabular}




\section{6: Primary cause of assault related admissions to Alice Springs Hospital}

\begin{tabular}{|c|c|c|c|c|c|c|c|c|c|c|c|}
\hline \multirow[b]{2}{*}{ Year } & \multirow[b]{2}{*}{ Total admissions } & \multicolumn{2}{|c|}{ Blunt } & \multicolumn{2}{|c|}{ Sharp } & \multicolumn{2}{|c|}{ Physical force } & \multicolumn{2}{|c|}{ Other $^{*}$} & \multicolumn{2}{|c|}{ Not recorded } \\
\hline & & $n$ & (\%) & $n$ & (\%) & $n$ & (\%) & $n$ & (\%) & $n$ & (\%) \\
\hline 1995-96 & 310 & 123 & $(39.7 \%)$ & 90 & $(29.0 \%)$ & 61 & $(19.7 \%)$ & 9 & $(2.9 \%)$ & 27 & $(8.7 \%)$ \\
\hline 1996-97 & 310 & 140 & $(45.2 \%)$ & 82 & $(26.5 \%)$ & 71 & $(22.9 \%)$ & 4 & $(1.3 \%)$ & 13 & $(4.2 \%)$ \\
\hline 1997-98 & 389 & 162 & $(41.6 \%)$ & 116 & $(29.8 \%)$ & 71 & $(18.3 \%)$ & 6 & $(1.5 \%)$ & 34 & $(8.7 \%)$ \\
\hline 1998-99 & 442 & 187 & $(42.3 \%)$ & 113 & $(25.6 \%)$ & 91 & $(20.6 \%)$ & 14 & $(3.2 \%)$ & 37 & $(8.4 \%)$ \\
\hline 1999-00 & 460 & 160 & $(34.8 \%)$ & 164 & $(35.7 \%)$ & 109 & $(23.7 \%)$ & 11 & $(2.4 \%)$ & 16 & $(3.5 \%)$ \\
\hline 2000-01 & 538 & 170 & $(31.6 \%)$ & 209 & $(38.8 \%)$ & 120 & $(22.3 \%)$ & 5 & $(0.9 \%)$ & 34 & $(6.3 \%)$ \\
\hline Total & 2449 & 942 & $(38.5 \%)$ & 774 & $(31.6 \%)$ & 523 & $(21.4 \%)$ & 49 & $(2.0 \%)$ & 161 & $(6.6 \%)$ \\
\hline
\end{tabular}

per 10000 people is only an estimate and is based on the predicted population at one point in time, it does support the proposition that Aboriginals make up a disproportionate number of hospital admissions for assault. Our study shows that serious assault resulting in admission to hospital is of real concern in the Aboriginal population, especially among women.

The association between alcohol use and violence is well known. ${ }^{14,15}$ Importantly, our data demonstrate a significant increase over time in the proportion of assault admissions associated with alcohol. Alcohol is the overriding substance-misuse issue of concern for people in Central Australia. Consensus as to how to address this problem has been difficult to achieve, and the problem continues to escalate. ${ }^{13}$ Many resources have been developed to assist healthcare workers, communities and individuals with alcohol and violence problems in the NT. ${ }^{16-19}$ That the rate of alcohol-related assault admissions has stopped increasing since 1997-98 may reflect positive effects of these health interventions. However, this pattern could also be explained, in part, by the adoption of ICD-10-AM codes for alcohol use in July 1998. The reasons for the levelling since 1997-98 need to be clarified.

Most assaults involved blunt objects; however, a substantial rise in the use of sharp objects is evident since 1999-00.

Our study uses "admissions to hospital" data. These data are useful because: - hospital admission data generally exclude more trivial assaults and injuries and are determined clinically by a qualified healthcare professional;
- presentations to the emergency department can be skewed by the availability of general practice services and other primary healthcare services, which can vary significantly over time; - alternatives such as self-report surveys contain inherent biases and are not suited to a large proportion of the Central Australian community, who are itinerant, poorly literate and "non-compliant" with such approaches.

Limitations of secondary data are well known and apply to our data ${ }^{20}$ - charting and coding may contain inaccuracies, be incomplete and be subject to coding bias, ${ }^{21-23}$ although false-positive comorbidities in the Australian population have been shown to be low. ${ }^{24}$

Despite these limitations, the data reveal major potential problems, suggesting the need for more rigorous, prospective investigation. The trend of increasing assault-related admissions is likely to continue if new measures are not implemented to curtail it. Clearly, assault-related admissions to hospital in the proportions described here suggest a significant public health problem that requires attention.

\section{COMPEING INTERESTS}

None identified.

\section{ACKNOWLEDGEMENTS}

We wish to thank Janine Wapper, Jill Burgoyne, Cathryn Klein and Wendy Mann for their assistance in the data extraction and collation process and to the anonymous reviewers who provided valuable suggestions on earlier versions of this manuscript.

\section{REFERENCES}

1. Koch T. Shameful: women blinded and disfigured as violence grips a community. Herald Sun (Melbourne) 2001; 29 June: 1-2.

2. Rintoul S. Break code of silence on violence: O'Donoghue. The Australian 2001; 18 Oct: 1.

3. Forde S. Domestic war zone. Koori Mail (Victoria) 1999; 15 Dec: 1, 4-5.

4. The Aboriginal and Torres Strait Islander Women's Taskforce on Violence Report. Brisbane: Department of Aboriginal and Torres Strait Islander Policy and Development, 2000.

5. Hunter E. Considering trauma in an Indigenous context. Aboriginal and Islander Health Worker Journal 1998; 22(5): 9-18.

6. Australian Bureau of Statistics. Crime and Safety. Canberra: ABS, 1999. (Catalogue no. 4509.0.)

7. Moller J. Understanding national injury data regarding Aboriginal and Torres Strait Islander peoples. Australian Injury Prevention Bulletin 14. Adelaide: National Injury Surveillance Unit, 1996. (AlHW Cat No. INJ-3.)

8. Moller J. Aboriginal and Torres Strait Islander people's injury-related hospitalisations 1991/92: A comparative Overview. Aboriginal and Islander Health Worker Journal 1997; 21(6): 12-14

9. NT estimated resident population by age, sex, Indigenous status and ATSIC regions. Epidemiology Branch, Department of Health and Community Services, 2002.

10. Taylor D, Eddy D, Cameron P. Demography of assault in a provincial Victorian population. Aust NZ J Public Health 1997; 21: 53-58.

11. Dempsey KE, Condon JR. Mortality in the Northern Territory 1979-1997. Darwin: Territory Health Services, 1999.

12. d'Abbs P, Togni S, Stacey N, Fitz J. Alcohol restrictions in Tennant Creek: a review prepared for the Beat The Grog Committee, Tennant Creek, Northern Territory. Darwin: Menzies School of Health Research, 2000.

13. Hauritz MA, Mcllwain G, Finnsson F. Dollars made from broken spirits. Alice Springs: determining its well-being and responsible alcohol management as part of everyday life. Report to the NT Licensing Commission. Alice Springs: Northern Territory Government and Alice Springs Town Council, 2000.

14. Stevenson RJ, Lind B, Weatherburn D. The relationship between alcohol sales and assault in New South Wales, Australia. Addiction 1999; 94: 397-410.

15. Stockwell T, Masters I, Philips M, et al. Consumption of different alcoholic beverages as predictors of local rates of assault, road crash and hospital admissions. Aust N Z J Public Health 1998; 22: 237-242. 
16. Brady M. Giving away the grog. Canberra: Commonwealth Department of Human Services and Health, 1995.

17. Brady M. Grog book. Canberra: Commonwealth Department of Human Services and Health, 1998

18. Territory Health Services. Living with alcohol: a handbook for community health teams. Darwin: Government Printer of the Northern Territory, 1998.

19. Gzik J, Hunter S. Domestic violence and employers. Darwin: Office of Women's Policy, Department of the Chief Minister, 1999.
20. Carr-Hill R. The measurement of inequities in health: lessons from the British experience. Soc Sci Med 1990; 31: 393-404.

21. Boyle CA, Dobson AJ. The accuracy of hospital records and death certificates for acute myocardial infarction. Aust N Z J Med 1995; 25: 316-323.

22. Accuracy of ICD-9-CM codes in hospital morbidity data, Victoria: implications for public health research. Aust N Z J Public Health 1997; 21: 477-482.

23. Khwaja HA, Syed H, Cranston DW. Coding errors: a comparative analysis of hospital and prospectively collected departmental data. BJU Int 2002; 87 178-180.

24. Powell H, Lim LL, Heller RF Accuracy of administrative data to assess comorbidity in patients with heart disease: an Australian perspective. J Clin Epidemiol 2001; 54: 687-693

(Received 14 Jan 2002, accepted 17 Jun 2002)

\section{book reviews}

\section{Must-have statistics}

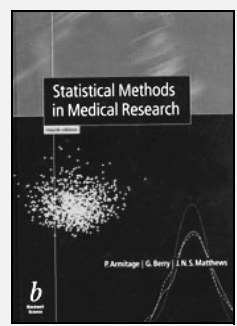

Statistical methods in medical research. 4th edition.

P Armitage, G Berry, J N S Mathews. Oxford:

Blackwell Science, 2002 (xi + 817 pp, \$193.60)

ISBN 0632052570

The CHANCE OF REVIEWING the new edition of this classic text came just at the right time, as my first edition copy had finally started to disintegrate. My introduction to medical statistics, or indeed any statistics apart from a brief encounter with experimental error assessment, came with the opportunity to sit in on Peter Armitage's lectures at the London School of Hygiene and Tropical Medicine in 1971. These lectures formed the basis of his book, and since then each edition has improved and expanded considerably on the last, keeping pace with the everchanging field of medical statistics and adding new coauthors on the way.

The book has been reorganised since the last edition, including, among other changes, new sections on permutation and Monte Carlo methods, non-linear regression and multilevel modelling, and also expanding the sections on Bayesian methods and clinical trials.

This book is about methods and their application and is aimed at the practitioner, but it is also suitable for anyone with an interest in statistics. It could be read as a unified text and could form the basis of a practice-oriented course, but it is most likely to be dipped into as required. The subject index appears extensive and exhaustive. There is also an excellent author index which helps to track down the context of any of the wide-ranging set of references. The authors do not present any mathematical theory; rather, they concentrate on commonsense explanation and justification for the techniques and methods that they describe, and these are accompanied by plenty of worked examples. They also direct readers to appropriate statistical software.

This book belongs on the shelf of anyone who uses or needs to understand anything about medical statistics, and will be constantly on loan from library shelves.

Nicholas H de Klerk

\section{Travel medicine - up to speed}

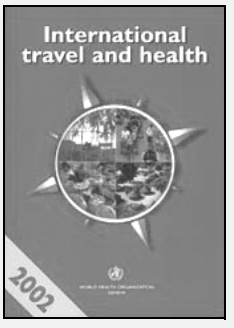

International travel and health. Geneva: World

Health Organisation, 2002 (viii + 193 pp, \$43) ISBN 9241580275

THE WORLD HEALTH ORganization has a measure of credibility when it comes to producing a book called International travel and health. Although this book is updated annually, in some years the most significant difference has seemed to be the change of colour to the stripe on the cover. The 2002 edition, though, is different!

The book has almost doubled in size, the cover has changed from the traditional yellow to a modern teal and, most significantly, there has been a change in the content. The claim on the cover of "abundant new material" is true. The list of acknowledgements reads like a "who's who" of travel medicine and their input has made the book up to date and value for money.

A diverse range of travel medicine topics are dealt with, from the traditional to the more unusual. Vaccinations, malaria, medical kits, altitude, deep vein thrombosis, jetlag, flight phobia, stings, worms, drownings, traffic accidents, muggings, travelling when pregnant, or with pre-existing medical conditions, and even risks from aircraft disinfection, ozone and cosmic radiation, are all dealt with. There is a particularly useful reference section summarising aspects of the infectious diseases that pose risks to travellers.

The book is organised logically with an extensive table of contents, index, excellent headings, and plenty of tables. The 12 maps in the centre give an excellent overview of the extent of various diseases in 2001 (eg, Japanese encephalitis, dengue, yellow fever, malaria, hepatitis A, B and C, rabies. The popular "Country List" remains - it outlines the current vaccination requirements and malaria situation for each country. This has limited value given the static nature of the publication, but takes up only 26 pages in a publication of 180 pages, so it does not detract too much from its general usefulness.

This 2002 edition is a great leap forward!

Deborah J Mills

Medical Director Travel Medicine and Vaccination Clinic, Brisbane, QLD 